\title{
Pubertal development of the pouch and teats in the marsupial Macropus eugenii
}

\author{
S. C. Nurse ${ }^{1 *}$ and M. B. Renfree ${ }^{2 *}$ \\ Departments of ${ }^{1}$ Physiology and ${ }^{2}$ Anatomy, Monash University, Clayton, Victoria 3168, Australia
}

\begin{abstract}
In the female tammar wallaby, Macropus eugenii, which has a highly seasonal breeding pattern, teat eversion and enlargement of the pouch occur at puberty, about 40 weeks after birth. The most obvious sign of puberty is teat eversion: 22 of 23 wild caught, and 23 of 24 captive postpubertal animals had fully everted or everting teats. Full eversion of the teats took on average two to three weeks after puberty. The pouch opening enlarged at puberty, and the rate of enlargement from 2 weeks before puberty to 2 weeks after puberty was significantly greater than the rate before puberty. In a group of pouch young ovariectomized at 5-10 weeks of age, no such changes in either teats or pouch were observed by 46 weeks of age. However, after treatment with oestradiol $\left(0.5 \mu \mathrm{g} \mathrm{kg}^{-1}\right.$ body mass), four of five young showed teat eversion within 3-4 weeks. Progesterone $\left(2 \mathrm{mg} \mathrm{kg}^{-1}\right)$ had no effect on inverted teats. In these ovariectomized females oestradiol treatment caused a significant increase in the rate of growth of the pouch opening. During progesterone injections the size of the pouch remained the same. Thus, at puberty the teats and pouch of the tammar wallaby undergo rapid developmental changes and growth. Ovariectomy at an early stage of gonadal differentiation disrupts these normal changes, but treatment of these animals with physiological doses of oestradiol at the age when puberty would normally have occurred can restore teat and pouch maturation. Teat eversion and pouch enlargement can therefore be used as markers for puberty. Both of these events appear to be under the control of ovarian oestradiol secretion.
\end{abstract}

\section{Introduction}

In many mammals the onset of puberty is heralded by the development of secondary sexual characteristics, such as the genital tumescence of certain primates, or growth of pubic hair and breasts in humans. Although marsupials do not have such obvious features, they do show pubertal changes in the teats and mammary glands. Teat eversion has proved a useful indicator for the onset of puberty in kangaroos (Poole and Catling, 1974), although the physiological changes responsible are not known.

The pouch also changes in appearance at about the time of puberty. In immature grey Eastern kangaroos, Macropus giganteus, and Western grey kangaroos, Macropus fuliginosus, the pouch is small, with a tight opening (Poole and Catling, 1974). Before the first offspring is born, the pouch opening becomes looser and the pouch deepens. After birth, the pouch enlarges with the growth of the pouch young. Once one pouch young has been raised to maturity, the pouch is much larger than in nulliparous animals, and never returns to the original size (Poole and Catling, 1974). In young, non-parous female

*Present address: Department of Zoology, Melbourne University, Parkville, Victoria 3052, Australia.

Received 15 September 1994. brushtail possums, Trichosurus vulpecula, the pouch, mammary glands and teats enlarge in January or February (Bolliger and Carrodus, 1939a). Premature changes in the pouch and mammary area comparable to these spontaneous changes can be induced in October by an injection of oestrone (Bolliger and Carrodus, 1938). Although pharmacological doses of relatively impure oestrogen were used, and the responses were not quantified, this early study nevertheless suggests a role for oestrogens in the control of pouch changes at about the time of puberty. The role of progesterone is less clear. Bolliger and Carrodus (1939b) found that weekly administration of high doses of progesterone to a single 3-month-old possum pouch young for 5 months initially caused a swelling in the pouch area and an increase in size of the mammary gland, but after 4 weeks of treatment the pouch and mammary gland regressed.

The tammar wallaby, Macropus eugenii, is a highly synchronized seasonally breeding marsupial, and most births occur in late January to early February. There is a postpartum oestrus about $\mathrm{I} \mathrm{h}$ after birth (Rudd, 1994) and a concomitant rise in oestradiol (Flint and Renfree, 1982; Shaw and Renfree, 1984; Harder et al., 1984) derived from the Graafian follicle (Harder et al., 1985). The conceptus from the postpartum mating grows to the blastocyst stage, and the blastocyst and its corpus luteum then remain in embryonic diapause and quiescence, respectively, until the following breeding season (reviewed in 
Tyndale-Biscoe and Renfree, 1987). Young remain in the pouch for about 40 weeks so that tammar young born in early February leave the pouch in late October and early November (Williams, 1990). Two-thirds of female young enter their first oestrus and mate at this time, and the resulting blastocyst and corpus luteum immediately become quiescent until the following January, when they give birth as do all the older females. The remaining third have all gone through puberty between November and late January.

In tammars, the initial differentiation of the pouch and mammary glands during fetal and neonatal life is not under steroidal control (Shaw et al., 1988), but the factors that control the maturational changes that occur at puberty are not known. The present study was designed to describe the changes in the teats and the pouch in the months before, and at, puberty in young female tammars, and to examine the role of gonadal steroids in this process.

\section{Materials and Methods}

\section{Animals}

Sixty-two young female tammars were shot in the wild on Kangaroo Island, South Australia in October and November after obtaining the required permits from the National Parks and Wildlife Service. Twenty-four young female tammars from a small breeding colony at Monash University, Melbourne, Victoria were examined three times a week from the time they left their mother's pouch until they themselves gave birth. Data from these animals are presented for the 10 weeks before puberty to the 4 weeks after puberty (that is, from about 30 weeks to 44 weeks postpartum). In March and April ten pouch young between 5 and 10 weeks of age (body mass $17.41 \pm 7.33 \mathrm{~g}$, mean $\pm \mathrm{SD}$; range $6.79-27.04 \mathrm{~g}$ ) were ovariectomized. Of these ten, six survived and were examined weekly from August, before their cohort of females would be expected to leave the pouch and go through puberty, until the following June, when all of the cohort would be expected to have 2-4-month-old pouch young. As the number of animals was limited, and the surgical procedure was difficult on these small heterothermic young, the ovariectomized animals could act as their own controls, because treatment did not start until March-April. Three intact female controls of the same age were similarly measured.

The pouches of an additional 17 mature, untreated females from the colony, carrying pouch young aged between 15 and 28 weeks, were measured in August.

\section{Definition of puberty}

In this study, puberty was defined as the first ovulation. This was identified retrospectively at autopsy by the presence of a single corpus luteum in the ovary in the wild tammars; for the colony animals oestrus and ovulation were detected by the presence of a semen plug in the urogenital sinus or an increase in progesterone concentration in the peripheral plasma indicative of an active corpus luteum.

\section{Measurement of follicles}

Ovaries from the Kangaroo Island animals were fixed in neutral-buffered formalin, serially sectioned at $7 \mu \mathrm{m}$, and every twentieth section was mounted and stained with haematoxylin and eosin. A projection microscope (Nikon Optiphot) was used to measure the follicles over $500 \mu \mathrm{m}$ in diameter from each ovary.

\section{Teat eversion and measurement of pouch opening}

Stage of teat development was noted for all animals and classified into three stages: (i) inverted; (ii) everting; (iii) everted, based on the descriptions given by Griffiths et al. (1972) and Poole and Catling (1974). 'Inverted' describes the earliest stage of teat development, when the teat is completely internal. 'Everted' describes the mature stage, where a teat protrudes from the mammary gland, and 'everting' is an intermediate stage when the teat region is raised, but the teat itself does not protrude. Data were not collected on the order of teat eversion. For each week, the proportion of the total number of teats for all animals (i.e. 24 animals $\times 4$ teats $=96$ teats) that are inverted is shown as a negative value, while the everted and everting teats are shown as a positive value. Data were synchronized at about the pubertal age of the animals. The pouch opening was measured (in $\mathrm{mm}$ ) by inserting the inside jaws of vernier callipers into the pouch opening, and stretching the pouch to a constant tension. A mean of two measurements was taken.

\section{Ovariectomy}

The ovariectomies were carried out when the pouch young were still heterothermic, and so they were anaesthetized by cooling. This is the recommended technique for carrying out surgery on small pouch young of macropodid marsupials, because it had been found to cause the least trauma (National Health and Medical Research Council, 1990). A fall in the body temperature of the young marsupial at this early stage of development slows the heart rate, and respiration may cease. Apnoea is not serious in these very small pouch young, as cutaneous exchange appears sufficient to maintain respiration (Renfree and Tyndale-Biscoe, 1978). These procedures were all approved by Institution Animal Experimentation Ethical committees, and conform to the Australian National Health and Medical Research Council guidelines.

After removal from their mother's pouch, the entire body of the pouch young was briefly immersed in a water bath maintained at $3^{\circ} \mathrm{C}$, and then placed on ice in a moist swab until the body movements stopped. It was then placed on an operating tray, consisting of an ice-filled Petri dish, covered with aluminium foil and a sterile swab and was held in position by loose rubber bands (Renfree and Tyndale-Biscoe, 1978). The surgery was performed under a binocular microscope. A lateral incision was made between each bottom rib and hind leg, and each ovary ligated, and excised. The wound was sutured using absorbable sutures. The pouch young were then rapidly warmed by hand, and to aid the animal in taking its first breath, the mouth was opened. In most cases the animal was pink, breathing and vigorous less than $10 \mathrm{~min}$ after the end of the 
Table 1. Proportion of young female tammar wallabies caught on Kangaroo Island in October and November with inverted, everted or everting (a combination of inverted and everted, as well as everting) teats, and the diameter (mean $\pm \mathrm{SD}$ ) of follicles over $500 \mu \mathrm{m}$

\begin{tabular}{lcccc}
\hline & Total number of animals & Four inverted teats & Everting teats & Four everted teats \\
\hline $\begin{array}{l}\text { Prepubertal } \\
\text { Mean follicle }\end{array}$ & 39 & 29 & 8 & 2 \\
$\quad$ diameter $(\mu \mathrm{m})$ & 23 & $765 \pm 172$ & $830 \pm 185$ & $898 \pm 119$ \\
Post-pubertal & $(n=23)$ & $(n=26)$ & $(n=12)$ \\
$\begin{array}{l}\text { Mean follicle } \\
\text { diameter }(\mu \mathrm{m})\end{array}$ & & 673 & $639 \pm 65$ & 12 \\
& $(n=1)$ & $(n=7)$ & $616 \pm 70$ \\
\end{tabular}

surgery. Operated young were returned to the pouch immediately after recovery and the mother's nipple was inserted into the mouth. Pouch young were checked for well-being for at least 3 days following surgery. In these six animals and a further three intact control animals of similar birth dates, growth (body mass and head length), and pouch opening diameter was recorded from August, when animals were $24.2 \pm 2.6$ weeks of age (mean $\pm \mathrm{SD}, n=9$ ), until June, when $64.6 \pm 2.9$ weeks of age (mean $\pm \mathrm{SD}, n=7$ ). One intact control animal died at 51 weeks, and one of the ovariectomized animals at 48 weeks. Stage of teat eversion was recorded from January (when animals were $40.2 \pm 2.6$ weeks, $n=9$ ) through until June.

\section{Steroid replacement treatment}

Owing to the limited number of animals, and the highly synchronized seasonal breeding pattern of tammar wallabies, the ovariectomized young acted as their own controls. Three weeks after all the intact young had gone through oestrus, ovulated and mated, a series of treatments was started in the ovariectomized animals. Oestradiol benzoate (Intervet International BV, Boxmeer) was diluted with arachis oil to $9.18 \mu \mathrm{mol} \mathrm{^{-1 }}\left(2.5 \mu \mathrm{g} \mathrm{ml}^{-1}\right)$ and an i.m. injection of $0.5 \mu \mathrm{g} \mathrm{kg}^{-1}$ body mass was given at intervals of 2 weeks (weeks 0, 2 and 4). Progesterone (Steraloids Inc., Wilton, $\mathrm{NH}$ ) was made up in arachis oil to a concentration of $12.72 \mathrm{mmol} \mathrm{l}^{-1}\left(4 \mathrm{mg} \mathrm{ml}^{-1}\right)$. An injection of $2 \mathrm{mg} \mathrm{kg}^{-1}$ body mass was given i.m. daily for 14 days starting on week 6 . Oestradiol injections were given again at weeks 11 and 12 . Observations were concluded 15 weeks after the first injection, which was 19 weeks after puberty had occurred in the controls.

\section{Statistical analysis}

Analysis of variance of repeated measures of individual animals and regression analysis (SPSS- $X$ information analysis system; Nie et al., 1986) were used to describe the expansion of the pouch opening. Pouch measurements of intact animals when prepubertal were compared with the pretreatment data for the ovariectomized animals. The initial oestradiol treatment period in the ovariectomized young was compared with the period around puberty in the intact animals. Where the regression equations did not overlap at the $95 \%$ confidence limits, these were taken to be significantly different rates of pouch enlargement. Pouch sizes of control animals at 65 weeks of age (about 20 weeks after puberty) and of normal adult females with young aged between 15-21 weeks and 24-28 weeks were compared by $t$ tests using the Minitab statistical program (Ryan et al., 1985). Teat eversion before versus after puberty was analysed using SAS (1985) Chi-square likelihood ratio statistical program.

\section{Results}

\section{Teat eversion}

The pattern of teat eversion in pre- and postpubertal animals was significantly different $(P<0.0001)$. Seventy-four per cent of the prepubertal animals on Kangaroo Island had inverted teats, whereas only $4.3 \%$ of the postpubertal animals had inverted teats (Table 1, Fig. 1). Only $5.1 \%$ of the prepubertal animals had four everted teats, while $52 \%$ of the postpubertal animals had four fully everted teats; $20.5 \%$ of the prepubertal and $43.5 \%$ of the postpubertal animals had everting teats. For these animals the category 'everting' includes animals with a combination of inverted and everted teats, as well as those with everting teats (Fig. 1). Of the eight prepubertal animals in this category, five of eight had all four teats everting, one had two everting and two everted, one had two inverted and two everted and the final one had two inverted and two everting. Of the ten postpubertal animals in this category, seven of ten had all four teats everting, and the remaining three had three everted and one everting teat. Both of the prepubertal animals with four everted teats had large follicles in the ovaries.

Twenty-three of the 24 Monash colony animals did not have any everted teats before puberty was detected (Fig. 2). After the first oestrus, ovulation and mating, the teats began to swell as round lumps, but the teat itself did not protrude from the mammary area (Fig. 1). During the next 2-3 weeks, the teats everted so that by the time of expected birth of the first young (about 29 days after oestrus) the teats were all everted. This full eversion of the teats by 4 weeks after puberty was found in all colony animals, including those that did not give birth but had one or more apparently infertile oestrous cycles. There was no difference in the timing of teat eversion between the animals that gave birth and the animals that had an apparently infertile cycle, and did not give birth. 

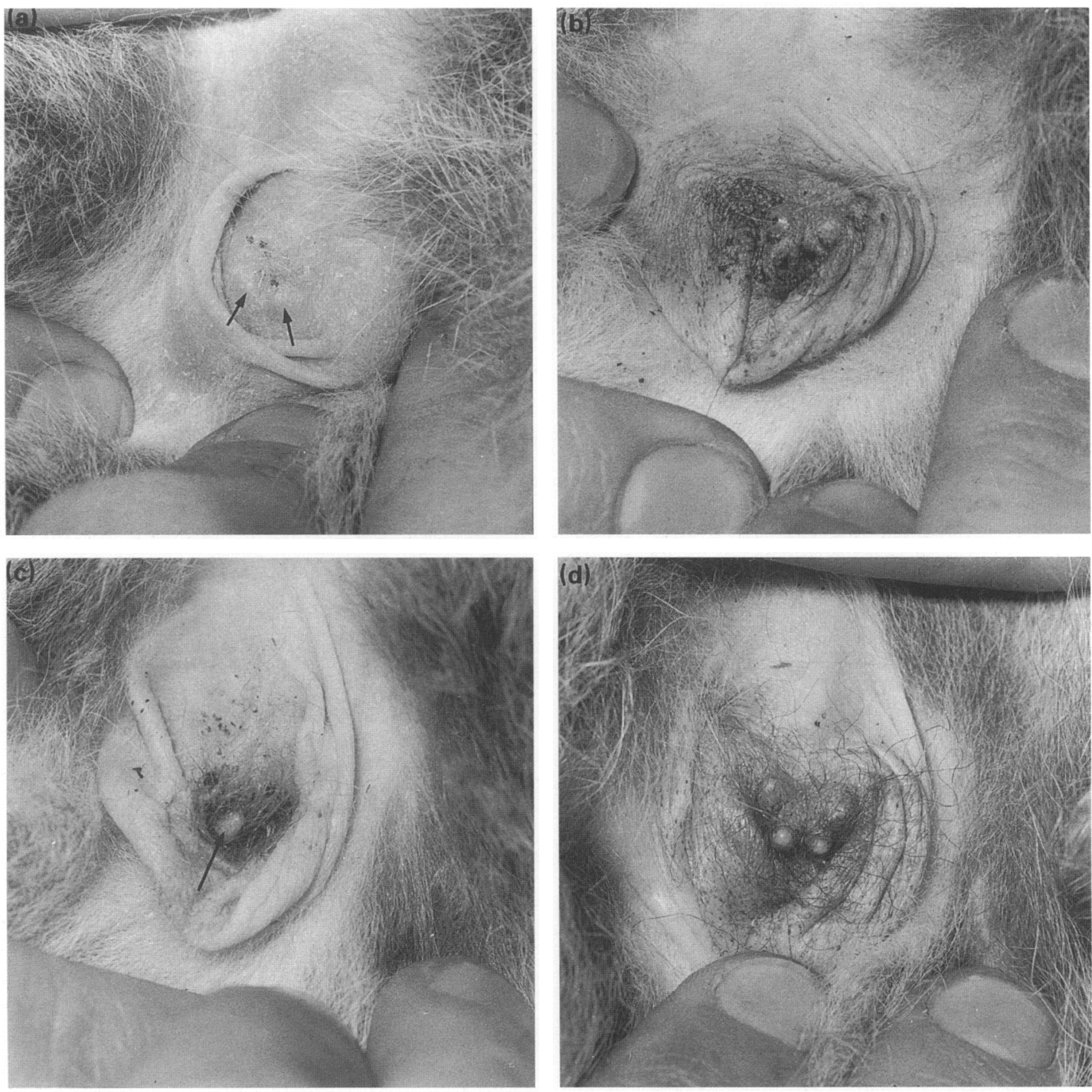

Fig. 1. Morphology of the developing pouch of tammar wallabies. (a) Inverted: the four teats of a tammar aged 43 weeks within the pouch are visible only as buds (arrows). (b) Everting: three of the four teats of a tammar aged 43 weeks are everted. (c) Everting: three of the four teats of a tammar aged 43 weeks are inverted and one fully everted (arrow). (d) Everted: all four teats of a 64-week-old tammar are fully everted.

The three intact young that served as normal controls for the ovariectomized young also had fully everted teats during their first oestrous cycle or pregnancy. The six ovariectomized young, however, all had teats that remained inverted until after the start of the steroid treatment (Fig. 3). Data are shown only for five of six of the ovariectomized animals, as one animal died of respiratory illness soon after the second oestradiol injection. The initial oestradiol benzoate injection did not induce immediate teat eversion in any of the young, but by week 3 and 4 after oestradiol injections began, four of the five young showed a number of everting or everted teats (Fig. 3). Progesterone treatment had little further effect on the remaining non-everted teats, but in one animal (with four everted teats), swollen mammary glands were observed after the progesterone injections. The resumption of the oestradiol injections caused the eversion of all but one of the remaining teats.

\section{Follicle size}

There was no statistically significant difference $(P>0.05)$ in the mean size of ovarian follicles over $500 \mu \mathrm{m}$ diameter between animals with inverted, everting or everted nipples for either the prepubertal or postpubertal animals (Table 1).

\section{Pouch growth}

At puberty in the intact young, the pouch opening enlarged. The rate of enlargement around puberty (from 2 weeks before to 2 weeks after) was significantly greater than the rate before puberty (from 22 to 43 weeks of age; Table 2). Two of the intact young gave birth 4 weeks after puberty, while the third had an apparently infertile cycle and did not give birth. Despite this, the pouch opening in the animals with neonatal pouch young was similar to that of the animal with no young. 


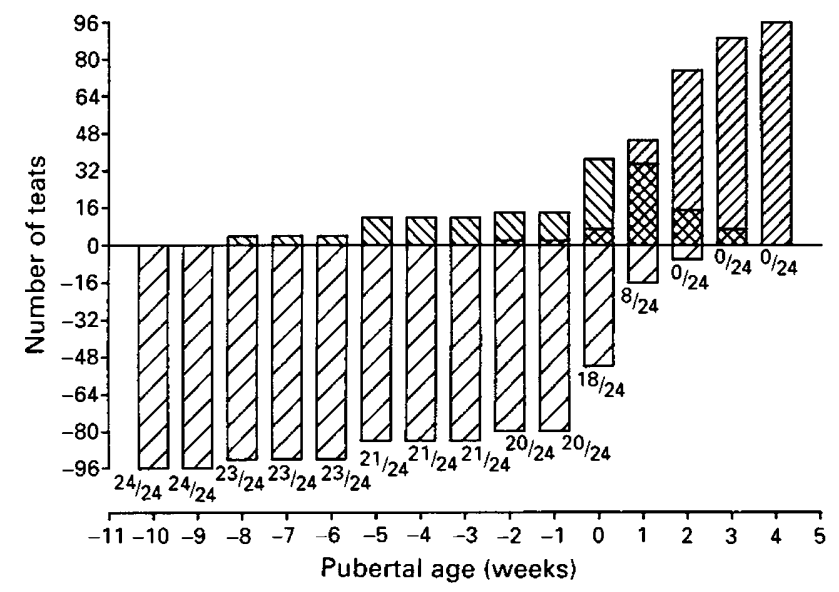

Fig. 2. Change in the proportion of $(\square)$ inverted, ( $\square)$ everting and (怾) everted teats in 24 young female tammar wallabies in the weeks leading up to puberty, and the following 4 weeks after either the first oestrous cycle, or the first pregnancy. All but one of the 96 teats are everted within two weeks of ovulation. Number of animals with four inverted teats compared with the total number of animals is shown for each week.
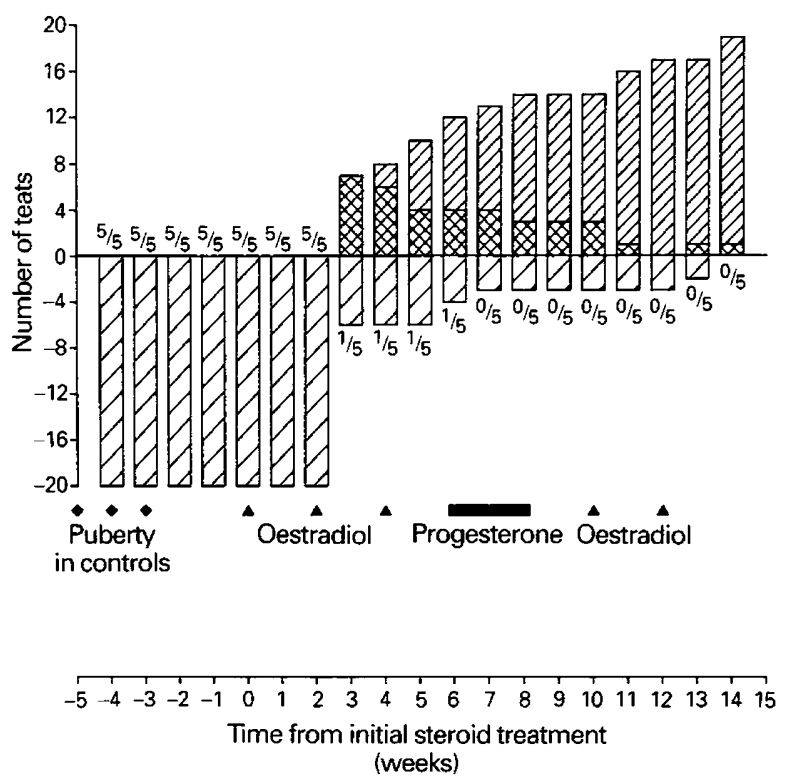

Fig. 3. Changes in the proportion of $(\square)$ inverted, $(\nabla)$ everting and ( $\triangle$ ) everted teats in ovariectomized young tammar wallabies after treatment with $0.5 \mu \mathrm{g}$ oestradiol $\mathrm{kg}^{-1}$ body mass or $2 \mathrm{mg}$ progesterone $\mathrm{kg}^{-1}$. Arrowheads show the individual oestradiol injections, and the bar shows the duration of progesterone injection. Number of animals with four inverted teats compared with the total number of animals is shown for each week. $(\bullet)$ Relative time of entry into puberty of control animals.

At the completion of the pouch measurements in the intact controls at 20 weeks after puberty (when their pouch young were 15-16 weeks old) their pouches measured $89.5 \pm 6.3$ (4.5) $\mathrm{mm}$ ( $\overline{\mathrm{x}} \pm \mathrm{SD}$ (SEM)) (Fig. 4). This is not significantly different from those of the five adults with young aged 15-22 weeks, the pouches of which were $99.4 \pm 11.7(5.2) \mathrm{mm}$ $(P>0.25)$. Adult females with young aged $24-28$ weeks had
Table 2. Growth rate of pouch opening in intact young tammar wallabies $(n=3)$ before and after puberty, and in ovariectomized young $(n=6)$ before and after treatment with $0.5 \mu \mathrm{g}$ oestradiol benzoate $\mathrm{kg}^{-1}$, in $\mathrm{mm}$ per week (range of $95 \%$ confidence limits in parentheses)

\begin{tabular}{|c|c|c|}
\hline & $\begin{array}{l}\text { Growth rate } \\
\text { intact young } \\
\left.\text { (mm week }^{-1}\right)\end{array}$ & $\begin{array}{c}\text { Ovariectomized } \\
\text { young } \\
\left(\mathrm{mm}^{-1} \text { week }^{-1}\right)\end{array}$ \\
\hline $\begin{array}{l}\text { Before puberty } \\
\text { or start of treatment }\end{array}$ & $\begin{array}{c}1.14 \\
(1.02-1.25)\end{array}$ & $\begin{array}{c}0.58 \\
(0.50-0.66)\end{array}$ \\
\hline $\begin{array}{l}\text { After puberty } \\
\text { or start of treatment }\end{array}$ & $\begin{array}{c}3.65 \\
(2.50-4.81)\end{array}$ & $\begin{array}{c}2.85 \\
(2.28-3.41)\end{array}$ \\
\hline
\end{tabular}

pouch openings of $123.5 \pm 1.23(3.5) \mathrm{mm}$, which was significantly different from that of the intact control group $(P>0.025)$ and from adults with 15-22-week-old young $(P>0.01)$. The pouch opening at 15-22 weeks after birth of the young was not much bigger than the mean head length $(56 \pm 5.5 \mathrm{~mm})$ of the contained young.

In the intact animals the pouch enlarged at a significantly greater rate (1.14 mm per week versus $0.58 \mathrm{~mm}$ per week) before puberty than in the ovariectomized young before the start of oestrogen treatment (Table 2). Regression analysis established that the expansion of the pouch opening with age was best described by a straight line. In the ovariectomized animals the initiation of the oestradiol treatment caused a significant increase in the rate of growth of the pouch opening, compared with the 23 weeks before treatment (when animals were 26-49 weeks of age). There was no significant difference between the rate of enlargement of the pouch opening in intact animals at puberty and in ovariectomized animals after oestradiol treatment (Fig. 4). Progesterone treatment had no effect on the size of the pouch opening.

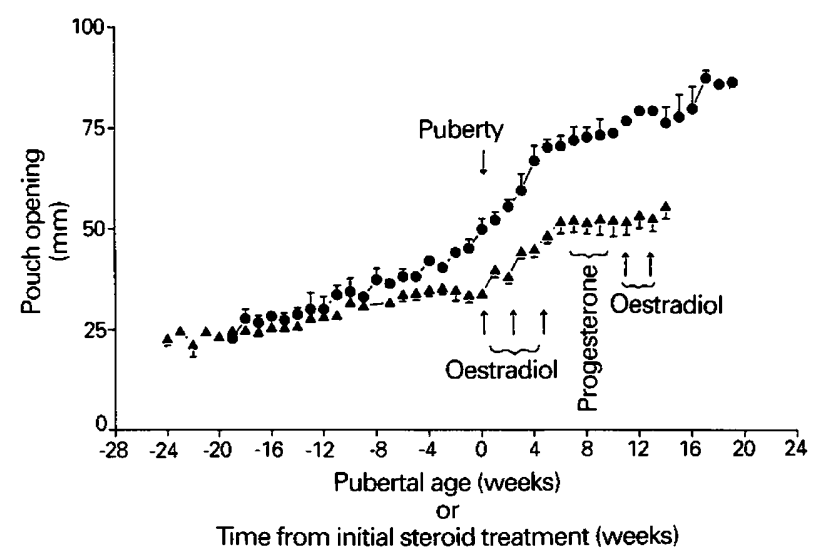

Fig. 4. Comparison of growth of the pouch opening in ( $\bullet$ intact young at the time of puberty and in $(\mathbf{\Lambda})$ ovariectomized young tammar wallabies after treatment with oestradiol $\left(0.5 \mu \mathrm{g} \mathrm{kg}^{-1}\right)$ and progesterone $\left(2 \mathrm{mg} \mathrm{kg}^{-1}\right)$. The animals are synchronized to pubertal age (intact young) or age at start of steroid treatment. 
In addition to causing teat eversion and growth of the pouch opening, the oestradiol injections enlarged the urogenital opening which became swollen and red. In some cases there was evidence of attempted mating by a male, as some of the animals had a semen plug in the urogenital sinus, and matted fur on the hindquarters, as is often found in young females after mating. In one female the urogenital opening was tom and bleeding on the day after one of the oestradiol injections.

\section{Discussion}

Normal pubertal development of the pouch and teats in the young tammar wallaby is dependent on ovarian secretions. At puberty, the pouch and the teats undergo rapid developmental changes and growth. Ovariectomy disrupts these normal developmental changes but treatment with physiological doses of exogenous oestradiol can restore them.

In Eastern and Western grey kangaroos the pouch increases in size, and the teats evert as the females approach sexual maturity, often with a transient everting stage (Poole and Catling, 1974), as was found in this study for the tammar. However, Poole and Catling (1974) did not find a consistent relationship between teat eversion and first oestrus, as teat eversion preceded first oestrus in some animals, and vice versa. However, it is possible that the time of first oestrus was missed. In tammars by contrast, the first oestrus precedes full teat eversion in most animals, but three exceptions were found in this study. Two of the animals caught on Kangaroo Island with everted teats were found on autopsy to be prepubertal, having only large follicles in the ovary. It is possible that these large follicles had produced sufficient oestrogen to effect teat eversion. One colony animal also had four everted teats at least 6 weeks before first detected oestrus. As no laparoscopy was performed it is not possible to tell whether the teat eversion was caused by large follicles, or by an earlier oestrous cycle that had not been detected.

All of the Monash young that had either an oestrous cycle or a pregnancy after the first oestrus had fully everted teats by the end of that cycle. Everted teats in the mother are obviously essential for the survival of the neonate, but as the same pattern was found in apparently non-pregnant females, development of the teats is independent of pregnancy. There is no difference between the development of the mammary gland during the oestrous cycle and during pregnancy in mature female tammars (Findlay, 1982). In addition, nulliparous female possums, red kangaroos Macropus rufus and tammars are capable of fostering and rearing neonatal young (Sharman, 1962; Sharman and Calaby, 1964; Findlay and Renfree, 1984). From the present study it is possible to add that there is no difference between teat eversion in pregnant and nonpregnant tammars immediately after puberty.

The postpubertal young animals caught on Kangaroo Island were in seasonal quiescence, as evidenced by a quiescent corpus luteum in their ovaries. Half of these animals had four everted teats, and another $43 \%$ had everting teats. At ovulation there is an increase in oestradiol concentrations (Shaw and Renfree, 1984; Harder et al., 1984). As it appears that in most animals teat eversion occurs $2-3$ weeks after a rise in oestradiol, it is assumed that these animals were examined within 2-3 weeks of their first oestrus. Only $4 \%$ (one animal) of postpubertal tammars had any inverted teats. Thus the Graafian follicles that ovulated and formed corpora lutea are assumed to be the source of the endogenous oestradiol which apparently controls the normal eversion of the teats. Progesterone must be less important in this process as these animals had not yet had an active pregnancy, and so their progesterone concentrations would be equivalent to those that occur during quiescence $\left(<200 \mathrm{pg} \mathrm{ml}^{-1}\right.$; Hinds and Tyndale-Biscoe, 1982). Ovariectomy of pouch young totally abolished normal maturation of the teats. Bolliger and Carrodus (1938) recorded a similar response to injections of pharmacological doses of oestrone in the brushtail possum. In the control intact tammars, teat eversion occurred, as normal, after the first oestrus, but no teat eversion was seen in the ovariectomized young until the second injection of oestradiol, 2 weeks after the start of the treatment. It is possible that the teats would have everted after a single injection, if more than 2 weeks had elapsed between injections. Progesterone administration did not appear to affect teat development, although it did cause apparent hypertrophy of the mammary gland in one animal. The final oestradiol injections caused the eversion of almost all the remaining teats. These data support the conclusion from the Kangaroo Island animals that ovarian oestradiol controls the development of the teats in the female marsupial.

The rate of increase of the linear diameter of the pouch opening was higher in the intact young just before and in the weeks after puberty compared with that of ovariectomized animals at the same age. The size of the pouch opening increased in the ovariectomized young after oestradiol injection, and the rate was then not significantly different from that of intact young at puberty. Like teat eversion, the increase in pouch size appears to be initiated by secretion of oestradiol from the Graafian follicle. The size of the pouch opening remained the same during the administration of physiological doses of progesterone. Subsequent injections of oestradiol after the period of progesterone treatment increased pouch size only marginally. The continued increase in size of the pouch opening in the intact young after puberty cannot be entirely ascribed to the stimulus (mechanical or otherwise) of a growing pouch young in the pouch, as there was no difference in the pouch opening between an intact young female that had an oestrous cycle but did not give birth after puberty, and the two other control females that had small pouch young. In females with older young, there appears to be a maximum size of the pouch opening, as all animals older than 150 days have pouch openings of $100-125 \mathrm{~mm}$.

Thus, teat eversion can be used as a marker for puberty in tammars. The enlargement of the pouch is also closely correlated with puberty; a rapid increase in the rate occurs just before the first oestrus. Both of these events appear to be under the control of ovarian oestradiol secretion.

The authors thank R. V. Short for suggestions in the planning of this study, and for helpful criticism of the manuscript. They especially thank T. P. Fletcher, G. Shaw and A. Liebert for assistance with the pouch measurements, R. Young for help with some of the ovariectomies, and D. Caddy for excellent advice on statistical procedures. This study was supported in part by Australian Research Council 
Programme grant no. A1851504 to R. V. Short and NH\&MRC grant no. 89/0457 to M. B. Renfree and R. V. Short. S. Nurse was supported by a Commonwealth Postgraduate Scholarship.

\section{References}

Bolliger A and Carrodus AL (1938) Changes in and around the pouch in Trichosurus vulpecula, as occurring naturally and as the result of the administration of oestrone Journal of the Proceedings of the Royal Society of NSW 71 615-622

Bolliger A and Carrodus AL (1939a) The effect of oestrogens on the pouch of the marsupial Trichosturus vulpecula Joumal of the Proceedings of the Royal Society of NSW 73 218-227

Bolliger A and Carrodus AL (1939b) The action of progesterone on the pouch of the marsupial Trichosurus vulpecula Journal of the Proceedings of the Royal Society of NSW $73 \quad 228-232$

Findlay L (1982) The mammary glands of the tammar wallaby (Macropus eugenii) during pregnancy and lactation Journal of Reproduction and Fertility 65 $59-66$

Findlay L and Renfree MB (1984) Growth, development and secretion of the mammary gland of macropodid marsupials Symposia of the Zoological Society, London 51 403-432

Flint APF and Renfree MB (1982) Oestradiol-17 $\beta$ in the circulation during seasonal reactivation of the diapausing blastocyst in a wild population of tammar wallabies, Macropus eugenii Joumal of Endocrinology 95 293-300

Griffiths M, McIntosh DL and Leckie RMC (1972) The mammary glands of the red kangaroo, with observations on the fatty acid components of the milk triglycerides Journal of Zoology 166 265-275

Harder ID, Hinds LA, Horn CA and Tyndale-Biscoe CH (1984) Oestradiol in follicular fluid and in utero-ovarian venous and peripheral plasma during parturition and post-partum oestrus in the tammar, Macropus engenii Joumal of Reproduction and Fertility 72 551-558

Harder JD, Hinds LA, Horn CA and Tyndale-Biscoe CH (1985) Effects of removal in late pregnancy of the corpus luteum, Graafian follicle or ovaries on plasma progesterone, oestradiol, LH, parturition and post-partum oestrus in the tammar, Macropus eugenii Journal of Reproduction and Fertility 75 449-459

Hinds LA and Tyndale-Biscoe CH (1982) Plasma progesterone levels in the pregnant and non-pregnant tammar, Macropus eugenii Journal of Endocrinology 93 99-107

National Health and Medical Research Council (1990) Australian Code of Practice for the Care and Use of Animals for Scientific Purposes. Commonwealth of Australia, Australian Government Publishing Service, Canberra, A.C.T.

Nie N, Bent DH and Hull CH (1986) SPSS-X Users' Guide (2nd edn). McGrawHill, New York

Poole WE and Catling PC (1974) Reproduction in the two species of grey kangaroo, Macropus giganteus (Shaw) and M. fuliginosus (Desmarest). I. Sexual maturity and oestrus Australian Joumal of Zoology 22 277-302

Renfree MB and Tyndale-Biscoe CH (1978) Manipulation of marsupial embryos and pouch young. In Methods in Mammalian Reproduction pp 307-331 Ed. JC Daniel. Academic Press, New York

Rudd CD (1994) Sexual behaviour of female and male tammar wallabies, Macropus engenii at post-partum oestrus Journal of Zoology 232 151-162

Ryan BF, Joner BL and Ryan TA (1985) Minitab Handbook (2nd Edn). Duxbury Press, Boston

Sharman GB (1962) The initiation and maintenance of lactation in the marsupial, Trichosurus vulpecula Journal of Endocrinology 25 375-385

Sharman GB and Calaby JH (1964) Reproductive behaviour in the red kangaroo, Megaleia rufa, in captivity CSIRO Wildife Research 9 58-85

SAS (1985) SAS/STAT Guide for Personal Computers Version 6. SAS Institute Inc., Cary NC

Shaw G and Renfree MB (1984) Concentrations of oestradiol-17 $\beta$ in plasma and corpora lutea throughout pregnancy in the tammar, Macropus eugenii Journal of Reproduction and Fertility 72 29-37

Shaw G, Renfree MB, Short RV and O W-S (1988) Experimental manipulation of sexual differentiation in wallaby pouch young with exogenous steroids Development 104 689-701

Tyndale-Biscoe CH and Renfree MB (1987) Reproductive Physiology of Marsupials. Cambridge University Press, Cambridge

Williams SC (1990) Puberty in the Female Tammar Wallaby. PhD thesis, Monash University 